\title{
DEVELOPMENT OF AN ELECTROCHEMICAL SENSOR MODIFIED WITH MWCNT-COOH AND MIP FOR DETECTION OF DIURON
}

\author{
Ademar Wong, ${ }^{\mathrm{a}, *}$, Marcos Vinicius Foguel ${ }^{\mathrm{a}}$, Sabir Khan ${ }^{\mathrm{a}}$, Fernanda Midori de Oliveirab \\ César Ricardo Teixeira Tarley ${ }^{\mathrm{b}}$, Maria D.P.T. Sotomayor ${ }^{\mathrm{a}}$ \\ a Department of Analytical Chemistry, Institute of Chemistry, State University of São Paulo (UNESP), 14801-970 Araraquara, SP, Brazil \\ b Department of Chemistry, State University of Londrina, Highway Celso Garcia Cid, km 380, 86050-482 Londrina, PR, Brazil
}

\section{A R T I C L E IN F O}

\section{Article history:}

Received 26 July 2015

Received in revised form 30 August 2015

Accepted 9 September 2015

Available online 11 September 2015

\section{Keywords:}

Diuron

electrochemical sensor

adsorption

molecularly imprinted polymer

MWCNT-COOH

\begin{abstract}
A B S T R A C T
An electrochemical sensor modified with a molecularly imprinted polymer (MIP) and carboxylfunctionalized multi-walled carbon nanotubes (MWCNT-COOH) was developed for the sensitive and selective detection of diuron in river water samples. An MIP was obtained by bulk polymerization using the best monomer (methacrylic acid) selected by computational simulation. The surface characteristics of the MIP and NIP (control polymer) samples were evaluated by means of surface area and pore volume determinations, using the BET method. The adsorption efficiency of the MIP was determined in adsorption tests that revealed high adsorption, relative to the control polymer. In addition, MWCNTs functionalized with carboxyl groups were used to enhance the performance of the sensor. Electrochemical studies of diuron using the MIP and MWCNT-COOH immobilized on a carbon paste electrode were performed with wave square voltammetry (SWV). The analytical parameters $\mathrm{pH}$, buffer composition, and amounts of MWCNT-COOH and MIP were investigated and optimized. Excellent results were obtained with a linear range of between $5.2 \times 10^{-8}$ and $1.25 \times 10^{-6} \mathrm{~mol} \mathrm{~L}^{-1}$, detection limit of $9.0 \times 10^{-9} \mathrm{~mol} \mathrm{~L}^{-1}$, and sensitivity of $5.1 \times 10^{5} \mu \mathrm{AL} \mathrm{mol}^{-1}$. The MWCNT-COOH-MIP/CPE showed an enhanced electrochemical response, with sensitivity 7.9-fold greater than for a plain carbon paste electrode (CPE). Application of the sensor using river water samples resulted in recoveries between 96.1 and $99.5 \%$ and $\mathrm{RSD}<5 \%(\mathrm{n}=3)$, demonstrating the reliability of this device.
\end{abstract}

(c) 2015 Elsevier Ltd. All rights reserved.

\section{Introduction}

Phenylurea herbicides such as diuron are widely used as selective pre- and post-emergence herbicides for the control of weeds in many agricultural crops including rice, sugar cane, coffee, corn, soybean, cotton, and potato [1,2]. Diuron can cause adverse effects in the environment, and human exposure to the compound can result in irritation to the eyes, skin, and mucous membranes, as well as formation of methemoglobin in the blood and abnormalities in the liver and spleen [3,4]. It also acts as an endocrine disruptor, interfering in the processes of release, transport, and disposal of natural hormones in the body $[4,5]$. Analytical methods for the determination of diuron that have been reported in the literature include spectrometric [6], chromatographic [7], fluorimetric [8], capillary electrophoretic [9], and electrochemical [10] techniques.

\footnotetext{
* Corresponding author. Tel.: +55 1633016620.

E-mail address: ademar.wong@hotmail.com (A. Wong).
}

The use of electrochemical sensors has attracted increasing research interest in recent years, due to attributes such as high stability, sensitivity, and selectivity. These methods are fast, inexpensive, miniaturizable, and offer good reproducibility, especially when the electrode is modified with substances including graphene, carbon nanotubes, ionic liquids, gold nanoparticles, inorganic compounds, organometallic complexes (phthalocyanine and porphyrin), and molecularly imprinted polymers (MIPs), amongst others [11,12]. The materials selected for use in this study were an MIP and multi-walled carbon nanotubes (MWCNTs).

The usefulness of molecularly imprinted polymers as electrochemical modifiers is due to their adsorptive and selective properties [13], and these materials offer a promising alternative method with great potential to resolve the limitations of separation techniques. An MIP can selectively adsorb an analyte (the template), performing a biomimetic recognition similar to that of an enzyme-substrate or an antibody-antigen system [14,15]. MIPs have been synthesized to suit a wide variety of templates, and are used as analytical tools that offer high sensitivity and selectivity, easy preparation, low cost, the possibility of synthesis 
Table 1

Monomers used in the computational simulation.

\begin{tabular}{|c|c|c|c|}
\hline Code & Monomer & & \\
\hline M1 & bis-acrylamide- $\mathrm{N}, \mathrm{N}$-methylene & M11 & methylene succinic acid \\
\hline M2 & imidazole-4-acrylic acid & M12 & methacrylic acid \\
\hline M3 & ethyl imidazole-4-acrylic acid ester & M13 & 3-divinylbenzene \\
\hline M4 & acrylic acid & M14 & 4-divinylbenzene \\
\hline M5 & acrylamide & M15 & styrene \\
\hline M6 & acrolein & M16 & 1-vinylimidazole \\
\hline M7 & allylamine & M17 & 2-vinylpyridine \\
\hline M8 & acrylonitrile & M18 & 4-vinylpyridine \\
\hline M9 & ethylene glycol dimethacrylate & M19 & 2-acrylamido-2-methyl-1-propane-sulfonic acid \\
\hline M10 & 2-(cyanoethylamine) ethyl methacrylate & M20 & 2-hydroxyethyl methacrylate \\
\hline
\end{tabular}

in the presence of any biomolecule (receptor molecules or enzymes), and resistance to adverse environments including exposure to acids, bases, organic solvents, and high temperatures $[15,16]$. The inclusion of MIPs in the design of sensors has been successfully used for the analysis of drugs [17], pesticides [18], dyes [19], metals [20], and ions [21].

Multi-walled carbon nanotubes are interesting nanomaterials that possess unique mechanical and electronic properties, such as chemical and thermal stability, elasticity, thermal and electrical conductivity, and mechanical resistance. Carbon nanotubes have been used in field emitters [22], quantum wires [23], batteries [24], and nanoelectronic devices [25]. Recent work has shown that MWCNTs can provide strong catalytic or electrocatalytic activity in electrochemical sensors [11,26].

This work describes the development of an electrochemical sensor based on carbon paste modified with an MIP and MWCNT$\mathrm{COOH}$. The device was used for the selective and sensitive detection of diuron in river water samples.

\section{Materials and Methods}

\subsection{Reagents and solutions}

All reagents were analytical or HPLC grade, as appropriate, and all solutions were prepared with deionized water (resistivity $\geq 18 \mathrm{M} \Omega$.cm at $25^{\circ} \mathrm{C}$ ) obtained from a Milli-Q Direct-0.3 purification system (Millipore).

Diuron, methacrylic acid, acrylic acid, azobisisobutyronitrile (AIBN), MWCNTs and trimethylolpropane trimethacrylate (TRIM) were obtained from Sigma-Aldrich. Sodium hydroxide, acetic acid, methanol, hydrochloric acid, and sodium dihydrogen phosphate were purchased from Synth (Brazil).

Stock solutions of $2.1 \times 10^{-5} \mathrm{~mol} \mathrm{~L}^{-1}$ diuron were prepared by dissolving $0.5 \mathrm{mg}$ of the compound in $0.5 \mathrm{~mL}$ of ethanol and diluting to $100 \mathrm{~mL}$ with deionized water.

(B)<smiles>O=C(O)COc1ccc(Cl)cc1Cl</smiles>

2,4-D

(D)<smiles>COC(=O)Nc1nc2ccccc2[nH]1</smiles>

Carbendazim<smiles>CSc1nnc(C(C)(C)C)c(=O)n1N</smiles>

Metribuzin

Chart 1. Chemical structure of pesticides analyzed in the selectivity test. 


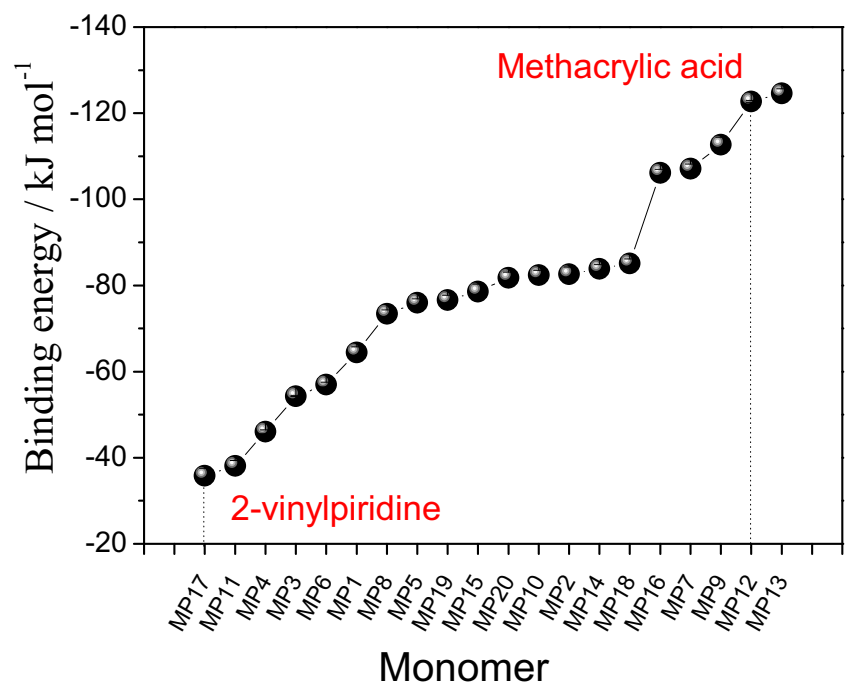

Fig. 1. Study of monomer-template interaction using computational simulation.

\subsection{Electrochemical measurements}

The electrochemical measurements were carried out using a potentiostat ( $\mu$ Autolab type III, Autolab/Eco Chemie) and a conventional electrochemical cell containing three electrodes: a commercial $\mathrm{Ag} / \mathrm{AgCl} / \mathrm{KCl}_{\text {sat }}$ reference electrode (Analion), a platinum coil as the counter electrode, and a modified carbon paste electrode as the working electrode (WE).

\subsection{Functionalization of the MWCNTs}

Functionalization of the MWCNTs consisted of mixing $100 \mathrm{mg}$ of multi-walled carbon nanotubes with $80 \mathrm{~mL}$ of a concentrated solution of nitric and sulfuric acids in a proportion of $3: 1(\mathrm{v} / \mathrm{v})$, respectively. This mixture was stirred for $12 \mathrm{~h}$ and then washed with deionized water until reaching $\mathrm{pH}$ 6.5-7.0. Afterwards, the MWCNTs were dried by heating at $70^{\circ} \mathrm{C}$ for $12 \mathrm{~h}$ [28].

\subsection{Synthesis of the molecularly imprinted polymer (MIP)}

Synthesis of the MIP and NIP polymers, using methacrylic acid or 2-vinylpyridine as the monomer, was performed by the bulk polymerization in solution method. First, the template molecule (diuron, $1.0 \times 10^{-4} \mathrm{~mol}$ ), $6 \mathrm{~mL}$ of porogenic solvent (acetonitrile), and the functional monomer $\left(4 \times 10^{-4} \mathrm{~mol}\right)$ were added to a glass tube and agitated for $2 \mathrm{~min}$ using a Vortex stirrer. After leaving the mixture to rest for $40 \mathrm{~min}$, the crosslinker (TRIM, $2 \times 10^{-3} \mathrm{~mol}$ ) was added, followed by agitation for $2 \mathrm{~min}$ and resting for $40 \mathrm{~min}$. Finally, the radical initiator (AIBN, $6.1 \times 10^{-5} \mathrm{~mol}$ ) was added and the mixture was bubbled with $\mathrm{N}_{2}$ for $8 \mathrm{~min}$. The glass tube was then sealed with Parafilm and placed in a water bath at $60^{\circ} \mathrm{C}$ for $24 \mathrm{~h}$ to allow total polymerization to occur $[29,30]$. The synthesized polymer was ground, sieved, and subjected to several washings in a volume of $100 \mathrm{~mL}$ methanol/acetic acid $(9: 1, \mathrm{v} / \mathrm{v})$ in a Soxhlet system, for $72 \mathrm{~h}$, for complete extraction of the analyte. The control polymer (NIP) was prepared in a similar way as the MIP, except that the template was not present. The extraction of diuron was monitored by high performance liquid chromatography (HPLC-UV) [31].
Table 2

Characterization of the porosity of the polymer using the BET method.

\begin{tabular}{llll}
\hline & \multicolumn{3}{l}{ Results of BET analysis for MIP and NIP } \\
\cline { 2 - 4 } Polymer & Surface area $\left(\mathrm{m}^{2} \mathrm{~g}^{-1}\right)$ & Pore volume $\left(\mathrm{cm}^{3} \mathrm{~g}^{-1}\right)$ & Diameter $(\mathrm{nm})$ \\
\hline MIP & 861 & 0.67 & 6.3 \\
NIP & 834 & 0.31 & 4.3 \\
\hline
\end{tabular}

2.5. Preparation of carbon paste modified with molecularly imprinted polymer (MIP) and carboxyl-functionalized multi-walled carbon nanotubes (MWCNT-COOH)

The preparation of the carbon paste was performed by mixing $90 \mathrm{mg}$ of graphite, $5.0 \mathrm{mg}$ of polymer (MIP or NIP (control polymer), and $5.0 \mathrm{mg}$ of MWCNT-COOH in $1.0 \mathrm{~mL}$ of $0.1 \mathrm{~mol} \mathrm{~L}^{-1}$ phosphate buffer solution ( $\mathrm{pH}$ 7.0). Phosphate buffer was used to blend the reagents and to contribute to the conductivity of the paste [27]. The material was carefully homogenized for 15 min using a mortar and pestle, and then left to dry at room temperature. About $85 \mu \mathrm{L}$ (90 mg) of mineral oil (Nujol) was added to the dry material to obtain the carbon paste. Preparation of the unmodified carbon paste and the paste modified with MWCNT employed $100 \mathrm{mg}$ of graphite and $95 \mathrm{mg}$ of graphite with $5 \mathrm{mg}$ of MWCNT, respectively, so that the amount of reagent used was $100 \mathrm{mg}$ in both cases. The same procedure was performed for other modifications in CPE.

A carbon paste electrode ( $\mathrm{CPE}$ ) was obtained by inserting the paste into the cavity of an electrode composed of a Teflon tube containing a platinum wire in contact with a $3 \mathrm{~mm}$ diameter platinum disc placed at a distance of $1.5 \mathrm{~mm}$ from one end of the tube, providing a cavity suitable for incorporation of the paste.

\subsection{Computational simulation}

The computational simulation employed computer programs to select the monomers most suitable for sensitive and selective MIP synthesis. Twenty monomers were evaluated, using the diuron molecule as a template (Table 1 ). The following programs were employed:

1) HyperChem 8.0.5 was used for the modeling of molecules.

2) OpenEye software package. The LIFE 3.0.0 program enabled visualization of the modeled molecules and checking of possible errors of bonds between atoms in the molecule. The Omega2 program was used to generate different conformers of the molecule, with three selected at random to perform the tests.

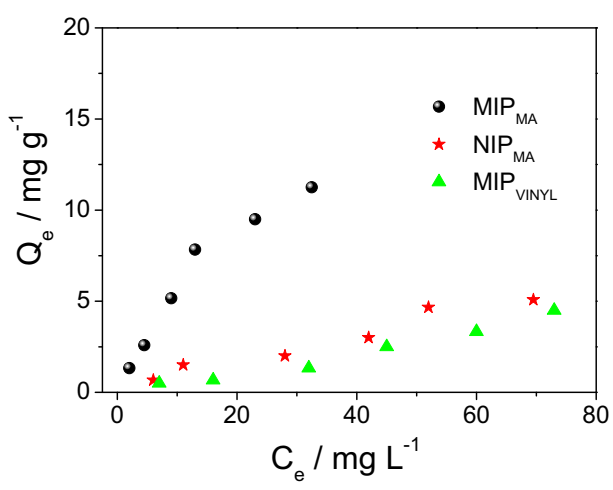

Fig. 2. Study of diuron adsorption by the MIP and NIP polymers. 


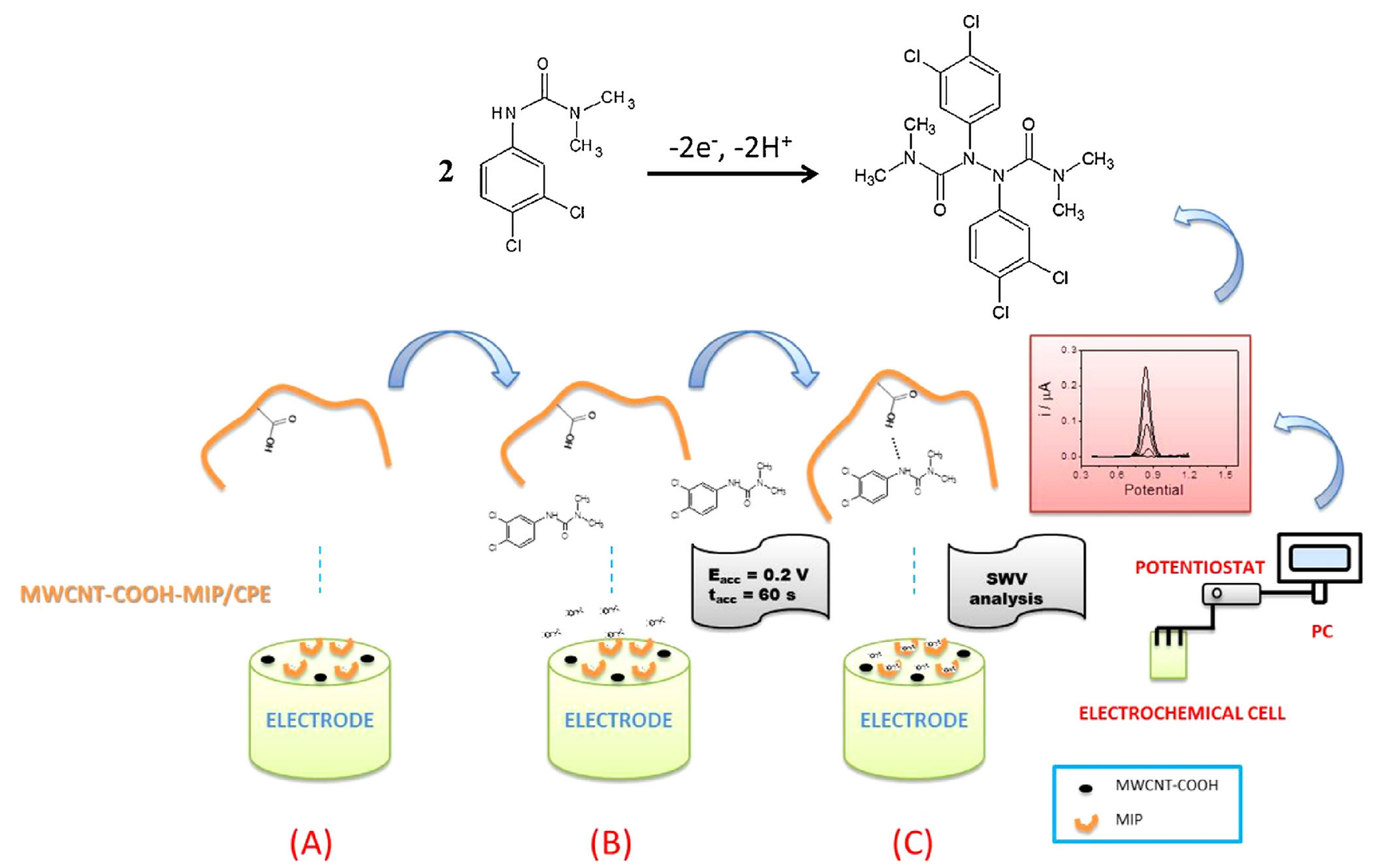

Fig. 3. Schematic illustration of interaction and electrochemical reaction of the diuron molecule using MWCNT-COOH and MIP on the electrode surface.

The Szybki 1.2.2 program was used to ensure that the molecule was in its lowest energy state.

3) The Autoit 3.3.6.0 application used command line scripts to automate repetitive processes during the molecular modeling, eliminating errors during the procedures.

4) The Multiple Minimum Hypersurfaces (MMH) with MOPAC (Molecular Orbital Package) program performed the approach of the monomers to the molecule to be used as a template, with calculation of the energy released resulting in affinity between the different components.

\subsection{Selectivity of the MIP in the electrochemical sensor}

The selectivity of the MWCNT-COOH-MIP/CPE was evaluated using a mixed solution of diuron and the pesticides carbofuran, carbendazim, metribuzin, and 2,4-D at concentrations of $4.0 \times 10^{-7}$ $\mathrm{mol} \mathrm{L}^{-1}$ (Chart 1 ). The pesticides were solubilized in deionized water and ethanol (20:1, v/v). Two solutions were employed for the analysis, one containing a diuron standard, and another containing all the pesticides. The analyses were carried out under optimized conditions using the square wave voltammetry (SWV) technique. The optimized analytical conditions were $\mathrm{f}=10 \mathrm{~Hz}, \mathrm{~A}=75 \mathrm{mV}$, $\Delta \mathrm{Es}=4 \mathrm{mV}$, and preconcentration using $\mathrm{t}_{\mathrm{acc}}=120 \mathrm{~s}$ and $\mathrm{E}_{\mathrm{acc}}=0.2 \mathrm{~V}$ vs. $\mathrm{Ag} / \mathrm{AgCl}$.

\subsection{Application of the sensor using river water samples}

The MWCNT-COOH-MIP/CPE was evaluated by analyzing enriched samples of river water collected at different locations near the city of Araraquara (around $270 \mathrm{~km}$ northwest of São Paulo, Brazil). Each sample was spiked with $4.0 \times 10^{-7} \mathrm{~mol} \mathrm{~L}^{-1}$ diuron, stirred for $10 \mathrm{~min}$ using a homogenizer, and then filtered to remove insoluble substances. The standard additions method was used for the determination of diuron in these spiked samples.

\subsection{HPLC analysis}

The equipment used was a Shimadzu 20A chromatograph fitted with a UV/visible detector (Model SPD-20A), an auto-injector (Model SIL-20A), and a degasser (Model DGU-20A5), coupled to a microcomputer. The stationary phase was a reversed phase C18 column (Shim-pack CLC, Shimadzu). The mobile phase was a mixture of acetonitrile and water $(70: 30 \mathrm{v} / \mathrm{v})$, the flow rate was $1.0 \mathrm{~mL} \mathrm{~min}^{-1}$, and the detector wavelength was $225 \mathrm{~nm} \mathrm{[31].}$

\section{Results and Discussion}

\subsection{Computational simulation}

The use of computational simulation as an analytical tool was very important for selection of the monomers used in the MIP synthesis. The interaction of each monomer with the template (diuron) was based on structural and functional affinity. No evaluation was made of physicochemical parameters or interaction of the template with the monomer at the molecular or electronic level. The energy released on approach between each monomer and the template (diuron) is shown in Fig. 1. Higher energy release (indicated by values that are more negative) was indicative of greater selectivity of the MIP, with increased affinity between the monomer and the template. Fig. 1 clearly shows that the MP12 and MP13 monomers presented better binding energies (around $-130 \mathrm{~kJ} \mathrm{~mol}^{-1}$ ), while MP17 had the lowest binding energy $\left(-36.5 \mathrm{~kJ} \mathrm{~mol}^{-1}\right)$. Hence, from the 20 monomers analyzed in the computational simulation, a monomer with high affinity (MP12, methacrylic acid) and a monomer with low binding energy (MP17, 2 -vinylpyridine) were selected for the purposes of comparison. 

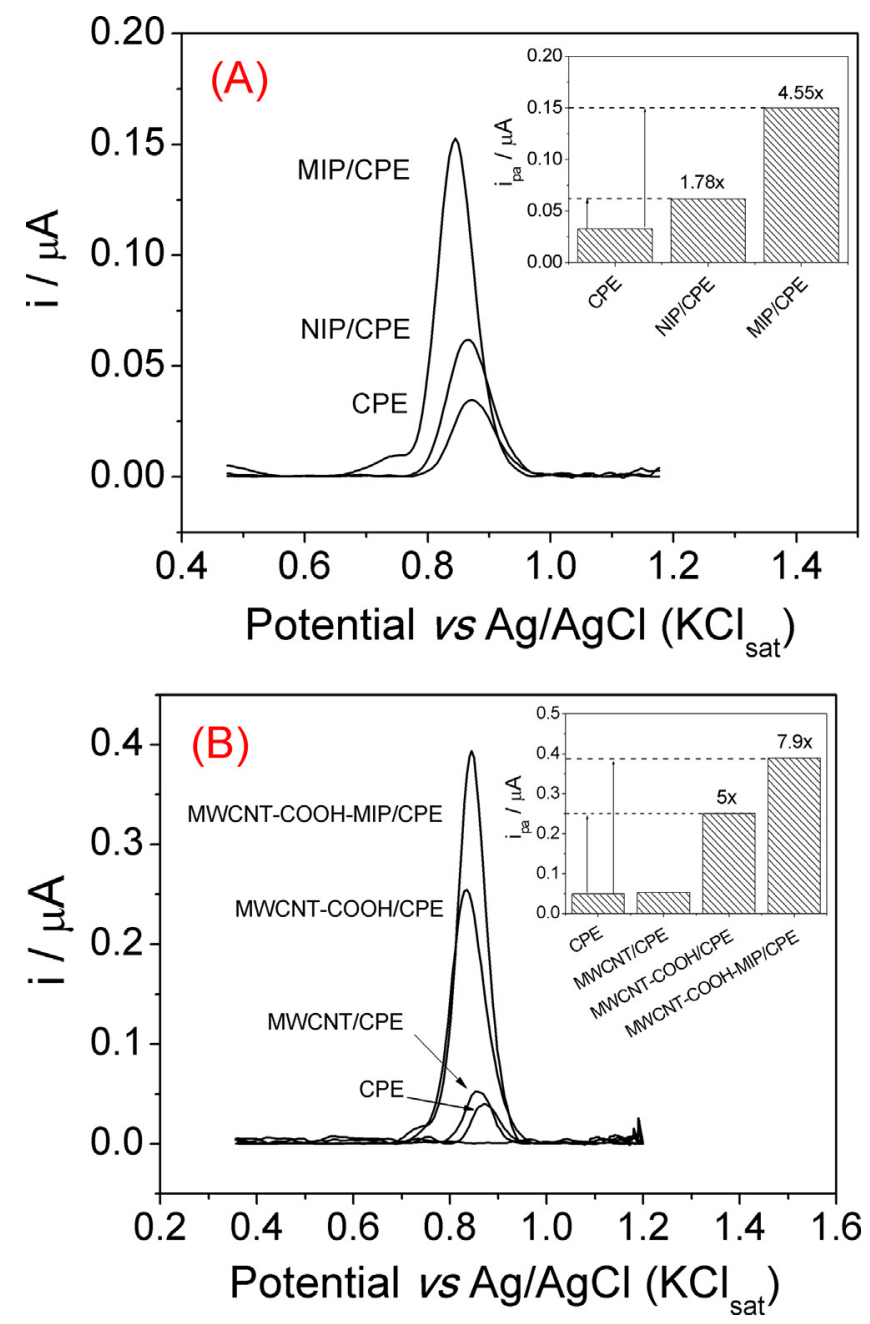

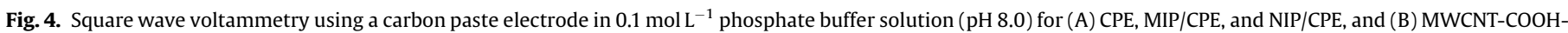

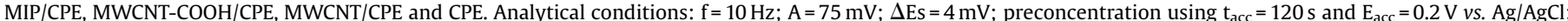
[diuron] $=4.0 \times 10^{-7} \mathrm{~mol} \mathrm{~L}^{-1}$.

MP13 was not used in the synthesis, because it was not a good polymerization agent.

\subsection{Porosimetry using the BET method}

The surface areas of the MIP and NIP polymers, measured using the BET method, were 861 and $834 \mathrm{~cm}^{2}$, the pore volumes obtained by nitrogen adsorption porosimetry were 0.67 and $0.31 \mathrm{~cm}^{3}$, and the pore diameters were 6.3 and $4.0 \mathrm{~nm}$, respectively (Table 2). Among all the parameters analyzed, the pore diameter was most important, because it approximated the size of the diuron molecule. The pore diameter and volume were smaller for the NIP, as expected because the MIP possessed a cavity that was complementary to the diuron molecule. It should be noted that in this study, the surface area was not a criterion used to ensure selectivity. The parameters that explained the results obtained with the MIP and NIP were the pore volume and diameter.

\subsection{Diuron adsorption}

The efficiencies of diuron adsorption by the MIP and NIP were evaluated using methacrylic acid and 2-vinylpyridine as monomers, and diuron concentrations in the range from 10 to $100 \mathrm{ppm}$. The optimized analytical conditions were $2 \mathrm{~h}$ adsorption time and pH 8.0 phosphate buffer solution. Fig. 2 shows plots of the amount of diuron adsorbed per $\mathrm{mg}$ of each polymer $\left(\mathrm{Q}_{\mathrm{e}}\left(\mathrm{mgg}^{-1}\right)\right)$, according to the amount of free diuron in solution $\left(\mathrm{C}_{\mathrm{e}}\left(\mathrm{mg} \mathrm{L}^{-1}\right)\right)$, calculated using:

$\mathrm{Q}=\left(\mathrm{C}_{0}-\mathrm{C}\right) \mathrm{V} / \mathrm{m}$

Table 3

Optimized square wave voltammetry (SVW) parameters.

\begin{tabular}{|c|c|c|}
\hline Parameter & Studied range & Optimum value \\
\hline Frequency $(\mathrm{Hz})$ & $10-40$ & 10 \\
\hline Amplitude (mV) & $25-100$ & 75 \\
\hline Increment $(\mathrm{mV})$ & $2-10$ & 4 \\
\hline Accumulation potential $\left(\mathrm{E}_{\mathrm{acc}}\right)$ & $-0.4-0.4$ & 0.2 \\
\hline Accumulation time $\left(\mathrm{t}_{\mathrm{acc}}\right)$ & $0-180$ & 120 \\
\hline
\end{tabular}



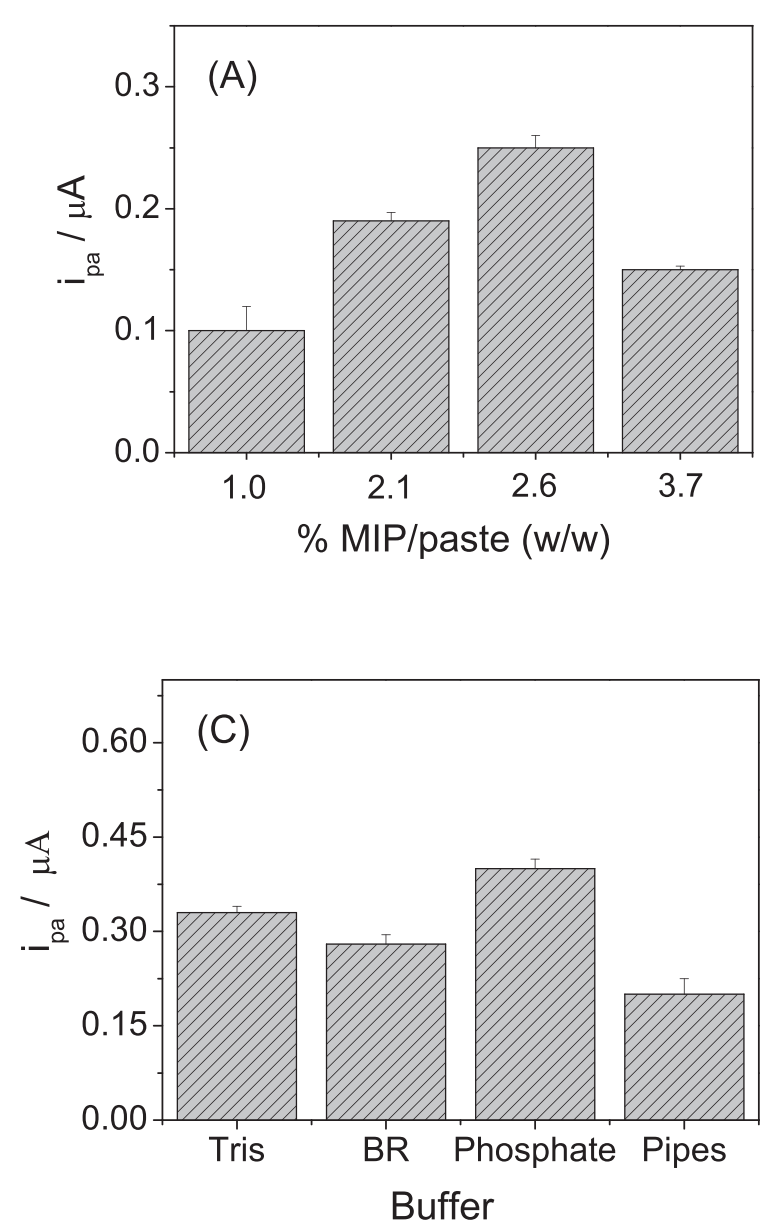
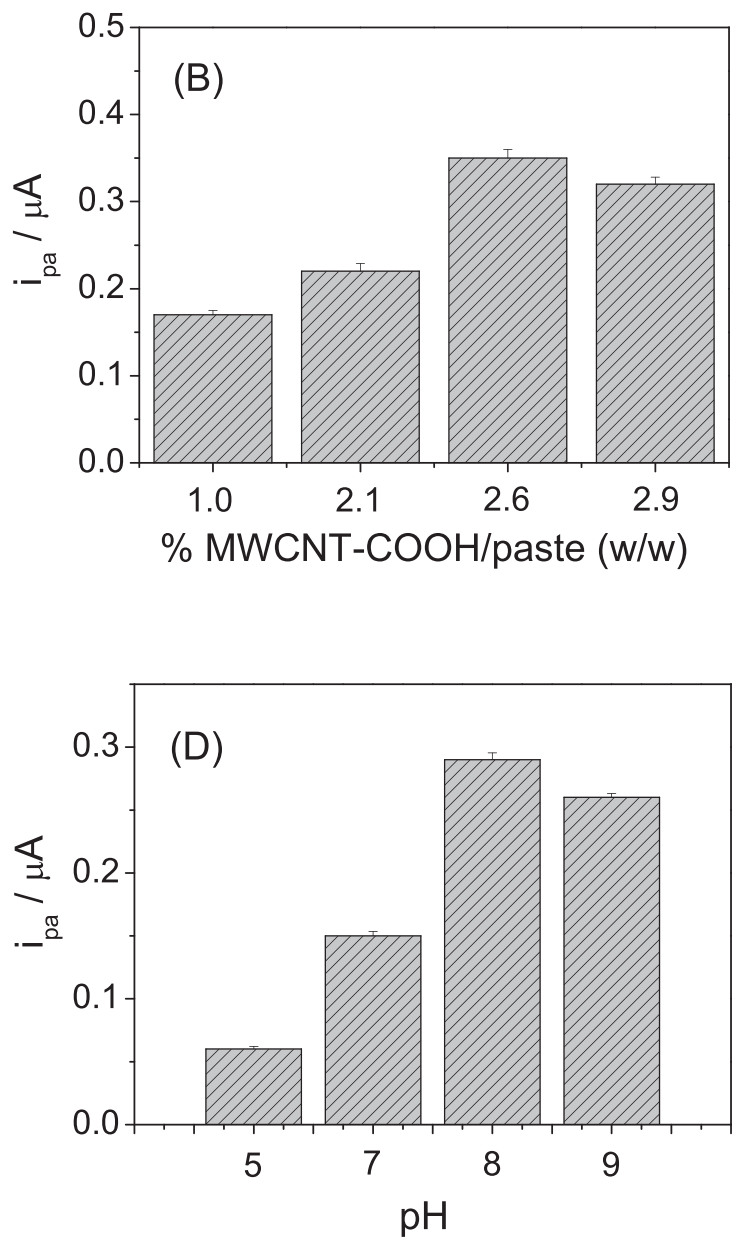

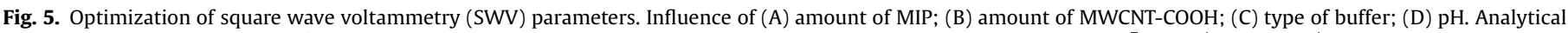

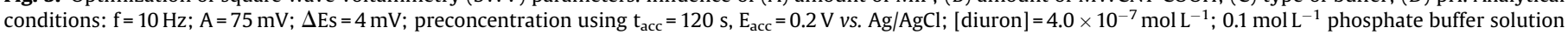
( $\mathrm{pH}$ 8.0) for experiments (A)-(C).

In Eq. (1), $\mathrm{C}_{0}$ is the initial diuron concentration $\left(\mathrm{mg} \mathrm{L}^{-1}\right), \mathrm{C}$ is the diuron concentration after adsorption, $\mathrm{V}$ is the volume of the solution of diuron in phosphate buffer $(\mathrm{mL})$, and $\mathrm{m}$ is the weight of the MIP or NIP $(\mathrm{g})$.

The adsorption of diuron onto the MIP was always greater than onto the NIP, for all concentrations tested, indicating that the imprinted polymer provided better molecular recognition. It should be noted that the adsorption study was used only to show the higher adsorption of diuron onto the MIP, compared to the NIP, and to compare the adsorption efficiencies of two MIPs synthesized with different monomers. The MIP synthesized with the methacrylic acid monomer showed better adsorption performance, compared to the use of 2-vinylpyridine, in agreement with the results obtained with the computational simulation. In this analysis, high performance liquid chromatography (HPLC) was employed to determine the amount of diuron adsorbed onto the polymer $\left(\mathrm{mg} \mathrm{ml}^{-1}\right)$, calculated by subtracting the concentration found by HPLC from the initial concentration added to the mixture.

\subsection{Interaction of the diuron molecule with the MIP and the MWCNT- $\mathrm{COOH}$ on the surface of the electrode}

The interaction between diuron and the MIP was studied using the optimum conditions identified previously. The interaction between the monomers and the template involved the amino groups of the template (diuron) and the hydrogen of the carboxyl group of the monomer. This same interaction occurred with the MWCNT-COOH. The use of the MWCNT-COOH and the MIP improved the performance of the electrochemical sensor by preconcentration of diuron on the electrode surface. Addition of the diuron solution to the electrochemical cell containing phosphate buffer resulted in its contact with the MIP and the MWCNT-COOH immobilized on the electrode surface, leading to interaction between the diuron molecules and the modifiers. This interaction was maximized using the optimal preconcentration potential and time $\left(t_{\mathrm{acc}}=120 \mathrm{~s}\right)$, as described in Section 3.3. Although both the MWCNT-COOH and the MIP possessed adsorptive properties, immobilization of the MIP on the surface of the electrode was mainly responsible for the enhanced sensitivity and selectivity of the sensor, due to the MIP-diuron affinity. Fig. 3 provides a schematic illustration of the interaction and the electrochemical reaction of the diuron molecule on the surface of the electrode. The electrochemical process is initiated after the preconcentration step, with the increase in potential (from 0 to $1.2 \mathrm{~V}$ ) promoting the oxidation reaction which involves two molecules of diuron forming a dimeric compound [10,32].

After obtaining the analytical curve, the electrode was washed with deionized water and ethanol $(10: 1, v / v)$ and then polished with clean paper to regenerate the surface. This procedure enabled many analytical curves to be constructed, showing that the longevity of the sensor was one of its main advantages. 


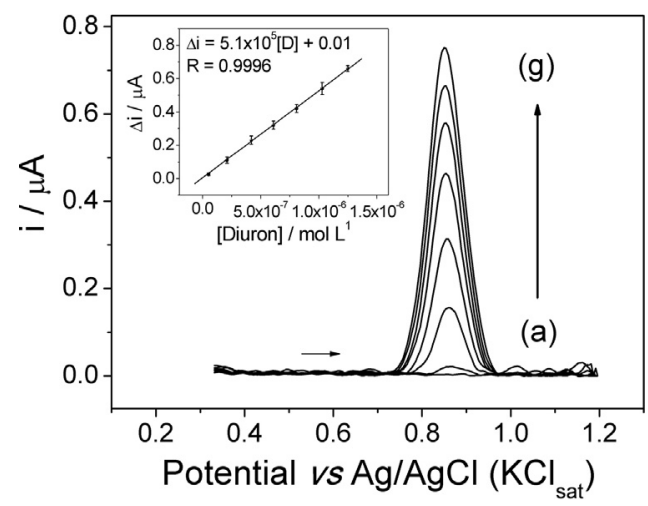

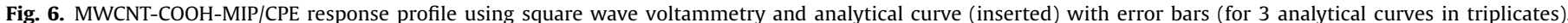

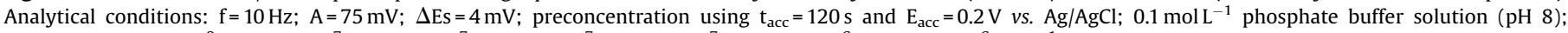
[diuron] = (a) $5.2 \times 10^{-8}$, (b) $2.1 \times 10^{-7}$, (c) $4.2 \times 10^{-7}$, (d) $6.1 \times 10^{-7}$, (e) $8.1 \times 10^{-7}$, (f) $1.03 \times 10^{-6}$, (g) $1.25 \times 10^{-6} \mathrm{~mol} \mathrm{~L}^{-1}$.

\subsection{Electrochemical behavior of diuron using the MWCNT-COOH-MIP/ CPE}

The electrochemical response obtained for diuron was studied in tests using the CPE, MIP/CPE, and NIP/CPE electrodes (Fig. 4A), and the CPE, MWCNT/CPE, MWCNT-COOH/CPE, and MWCNTCOOH-MIP/CPE electrodes (Fig. 4B). The results showed that better electrochemical signals were achieved for the MIP/CPE, relative to the NIP/CPE and the CPE, and for the MWCNT-COOH-MIP/CPE, relative to the MWCNT/CPE, MWCNT-COOH/CPE, and CPE. Improved electronic transfer achieved using the MIP and the MWCNT-COOH resulted in enhanced sensor sensitivity. The higher anodic peak currents $\left(\mathrm{I}_{\mathrm{pa}}\right)$ obtained with the use of the modifiers are shown in Fig. 4.

The effect of accumulation potential $\left(\mathrm{E}_{\mathrm{acc}}\right)$ and time $\left(\mathrm{t}_{\mathrm{acc}}\right)$ on the anodic peak current of the MWCNT-COOH-MIP/CPE was evaluated in the presence of $4.0 \times 10^{-7} \mathrm{~mol} \mathrm{~L}^{-1}$ diuron. The best values were $\mathrm{E}_{\mathrm{acc}}=0.2 \mathrm{~V}$ and $\mathrm{t}_{\mathrm{acc}}=120 \mathrm{~s}$. Other optimized parameters of SWV are presented in Table 3. The optimum amount of MIP in the carbon paste was $2.6 \%(\mathrm{w} / \mathrm{w})$ (Fig. $5 \mathrm{~A})$. The highest anodic peak current $\left(\mathrm{i}_{\mathrm{pa}}\right)$ intensity was obtained using $2.6 \%(\mathrm{w} / \mathrm{w})$ MWCNT-COOH and phosphate buffer ( $\mathrm{pH}$ 8.0) (Fig. 5B,C, and D).

The peak currents obtained by square wave voltammetry were measured using successive additions of diuron stock solution $\left(2.1 \times 10^{-5} \mathrm{~mol} \mathrm{~L}^{-1}\right)$. The determination of diuron was performed at a potential of $0.85 \mathrm{~V}$ vs. $\mathrm{Ag} / \mathrm{AgCl}$. The sensor showed a linear response to diuron concentrations between $5.2 \times 10^{-8}$ and $1.25 \times 10^{-6} \mathrm{~mol} \mathrm{~L}^{-1}$, sensitivity of $5.1 \times 10^{5} \mu \mathrm{AL} \mathrm{mol}^{-1}$, and detection limit (LOD) of $9.0 \times 10^{-9} \mathrm{~mol} \mathrm{~L}^{-1}(3 \times \mathrm{SD} / \mathrm{m}$, where SD is the standard deviation for measurements of the blank solution $(n=10)$, and $\mathrm{m}$ is the slope of the analytical curve) (Fig. 6) [33]. The relative standard deviation (RSD) obtained for five analytical curves was $2.9 \%$, demonstrating the high reproducibility and stability of the proposed sensor. A comparison was made between the square wave voltammetry and differential pulse voltammetry techniques (not shown), with SWV showing the highest sensitivity in the electrochemical measurements.

Comparison of the performance of the proposed sensor with that of other electrochemical sensors (Table 4) showed the superiority of the new method in terms of linear range and detection limit. Advantages include the possibility of direct detection, high stability and reproducibility, low detection limit, and the ability to renew the electrode surface by simple washing with deionized water and ethanol $(10: 1, \mathrm{v} / \mathrm{v})$, followed by polishing with clean paper. In addition, a large number of analyses can be performed in a relatively short time (about 30 analyses per hour), at a low cost.

\subsection{Selectivity of the sensor in the presence of other pesticides}

Fig. 7 shows the results obtained for the selectivity of the MWCNT-COOH-MIP/CPE in the presence of other pesticides. Square wave voltammetry in the potential range from 0 to $1.2 \mathrm{~V}$ was used to evaluate the electrochemical responses obtained for the pesticides, which have redox activity. In this analysis, it was confirmed that only diuron showed a measurable electrochemical response, with an anodic peak current $\left(i_{\text {pa }}\right)$ at a potential of $850 \mathrm{mV}$ vs. $\mathrm{Ag} / \mathrm{AgCl} / \mathrm{KCl}_{\text {sat }}$, indicating the high selectivity of the proposed sensor. The concentrations of the pesticides used were $4.0 \times 10^{-7}$ $\mathrm{molL}^{-1}$. It was also found that during preconcentration, the adsorbed pesticides did not affect the intensity of the analytical signal for diuron.

\subsection{Application to river water samples}

Application of the sensor using three river water samples resulted in recoveries of between 96.1 and $99.5 \%$ for the proposed technique, while recoveries for the comparative HPLC method

Table 4

Comparison of the performances of different electrochemical sensors for the determination of diuron.

\begin{tabular}{|c|c|c|c|c|}
\hline Electrode & $\begin{array}{l}\text { Dynamic range } \\
\left(\mathrm{mol} \mathrm{L}^{-1}\right)\end{array}$ & Detection limit $\left(\mathrm{mol} \mathrm{L}^{-1}\right)$ & Technique & References \\
\hline Screen printed $(\mathrm{OCP})^{\mathrm{a}}$ & $2.1 \times 10^{-6}-4.6 \times 10^{-6}$ & $2.1 \times 10^{-6}$ & amperometry & [10] \\
\hline GCE (NiTAPC) ${ }^{\mathrm{b}}$ & $0.3 \times 10^{-6}-3.0 \times 10^{-4}$ & $3.3 \times 10^{-7}$ & amperometry & [34] \\
\hline $\mathrm{Au}(\mathrm{LC}-\mathrm{LAGE})^{\mathrm{C}}$ & $1.0 \times 10^{-12}-1.0 \times 10^{-6}$ & - & SWV & [35] \\
\hline Screen printed (PSII complex) ${ }^{\mathrm{d}}$ & $1.3 \times 10^{-10}-4.3 \times 10^{-5}$ & - & amperometry & [36] \\
\hline MWCNT-COOH-MIP/CPE & $5.2 \times 10^{-8}-1.25 \times 10^{-6}$ & $9.0 \times 10^{-9}$ & SWV & This work \\
\hline
\end{tabular}

a Screen-printed electrode modified with organic conjugated polymers.

b Glassy carbon electrode (GCE) modified with polymerized nickel tetraamino-phthalocyanine.

c Au electrode fabricated on polystyrene substrate (immunosensor).

d The screen printed biosensor consisted of the PSII complex (biosensing element) isolated from the thermophilic cyanobacterium Synechococcus elongatus f. thermalis. 


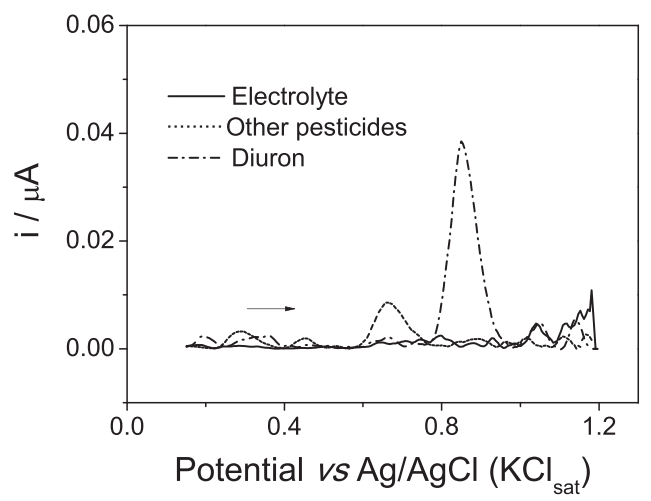

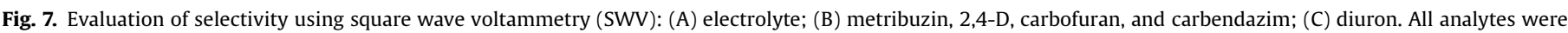

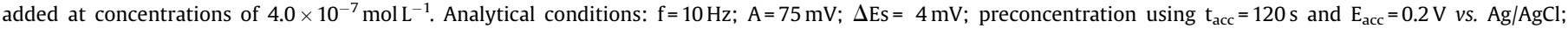
$0.1 \mathrm{~mol} \mathrm{~L}^{-1}$ phosphate buffer solution ( $\mathrm{pH} 8.0$ ).

Table 5

Recovery values found with the MWCNT-COOH-MIP/CPE for river water samples after enrichment with diuron ( $\mathrm{n}=3$ ).

\begin{tabular}{|c|c|c|c|c|c|c|}
\hline \multirow[t]{3}{*}{ River sample } & \multicolumn{6}{|c|}{ [Diuron] $/ \mathrm{mol} \mathrm{L}^{-1}$} \\
\hline & \multicolumn{3}{|c|}{ Proposed method } & \multicolumn{3}{|c|}{ HPLC method } \\
\hline & $\overline{\text { Added }}$ & Found $^{\mathrm{a}}(\% \mathrm{RSD})$ & Recovery (\%) & $\overline{\text { Added }}$ & Found ${ }^{\mathrm{a}}$ (\%RSD) & $\overline{\text { Recovery (\%) }}$ \\
\hline Chibarro & $5.2 \times 10^{-8}$ & $5.04 \times 10^{-8}(3.5)$ & 96.1 & $2.1 \times 10^{-5}$ & $2.02 \times 10^{-5}(4.5)$ & 96 \\
\hline Jacaré-Pepira & $5.2 \times 10^{-8}$ & $5.12 \times 10^{-8}(4.8)$ & 98.5 & $2.1 \times 10^{-5}$ & $2.06 \times 10^{-5}(5.0)$ & 98 \\
\hline Jacaré-Guaçu & $5.2 \times 10^{-8}$ & $5.17 \times 10^{-8}(1.5)$ & 99.5 & $2.1 \times 10^{-5}$ & $2.08 \times 10^{-5}(5.5)$ & 99 \\
\hline
\end{tabular}

a Average of 3 measured concentrations; RSD $=\sigma / \mu \times 100$ ( $\sigma=$ standard deviation of 3 measured concentrations; $\mu=$ average of 3 measured concentrations).

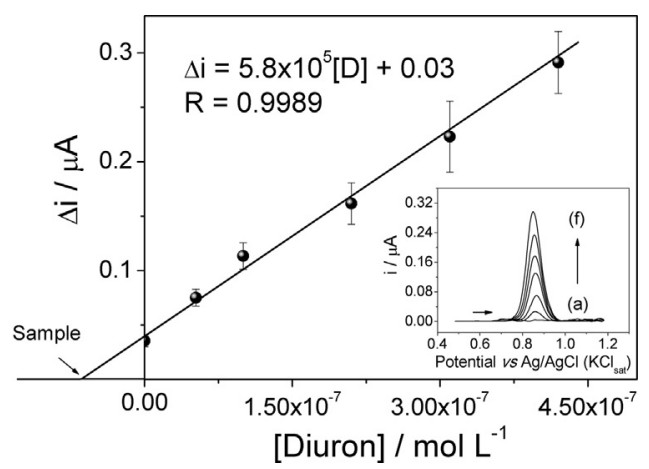

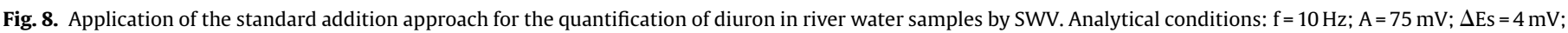

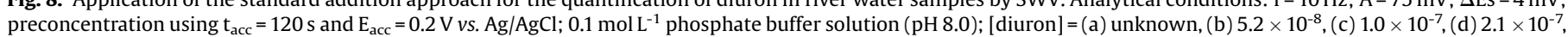
(e) $3.1 \times 10^{-7}$, (f) $4.2 \times 10^{-7} \mathrm{~mol} \mathrm{~L}^{-1}$.

were between 96 and 99\% (Table 5). These findings were indicative of an absence of matrix effects. The RSD values were lower than $5 \%$ $(\mathrm{n}=3)$, showing the high accuracy and reproducibility achieved with the proposed sensor. Fig. 8 shows the electrochemical determination of diuron with the MWCNT-COOH-MIP-CPE, using the standard additions method.

In these experiments, the proposed sensor was able to detect diuron at a concentration of $5.2 \times 10^{-8}$, while the HPLC method could only detect $2.1 \times 10^{-5} \mathrm{~mol} \mathrm{~L}^{-1}$ of diuron. Other advantages of the proposed sensor, relative to HPLC, were lower consumption of reagents, short analysis time, high selectivity and sensitivity, low cost, and the ability to analyze samples without any need for pretreatment. These characteristics emphasize the contribution that electrochemical sensors can make as alternative tools for the determination of analytes of interest.

\section{Conclusions}

This work describes the successful use of a molecularly imprinted polymer and MWCNT-COOH as modifiers on an electrode surface. The new analytical method was shown to be practical and provided accurate determination of diuron, with excellent sensitivity and selectivity. The catalytic and adsorptive properties of MWCNT-COOH, together with the selective and adsorptive properties of MIP, enhanced the electrochemical signal of the proposed sensor, enabling satisfactory determination of diuron in river waters. In recovery studies, the MWCNT-COOHMIP/CPE showed RSD less than $5 \%$, indicating the suitability of the proposed method for use in practical applications. Computational simulation was successfully used as an analytical tool for selection of the best monomer employed for the synthesis of the MIP. 


\section{Acknowledgments}

The authors are grateful for financial support provided by FAPESP (Proc. 2011/03008-7 and 2014/25264-3).

\section{References}

[1] J.E. Cullington, A. Walker, Rapid biodegradation of diuron and other phenylurea herbicides by a soil bacterium, Soil Biol. Biochem. 31 (1999) 677-686.

[2] S. Giacomazzi, N. Cochet, Environmental impact of diuron transformation: a review, Chemosphere 56 (2004) 1021-1032.

[3] G.S.A. Ferdandes, A.C. Arena, C.D.B. Fernandez, A. Mercadante, L.F. Barbisan, W. G. Kempinas, Reproductive effects in male rats exposed to diuron, Reprod. Toxicol. 23 (2007) 106-112.

[4] D.C. Gooddy, P.J. Chilton, I. Harrison, A field study to assess the degradation and transport of diuron and its metabolites in a calcareous soil, Sci. Tot. Environ 297 (2002) 67-83.

[5] M.A. Castillo, N. Felisa, P. Aragon, G. Cuesta, C. Sabater, Biodegradation of the herbicide diuron by streptomyces isolated from soil, Int. Biodeterior Biodegrad. 58 (2006) 196-202.

[6] A.M. Rodrigues, V. Ferreira, V.V. Cardoso, E. Ferreira, M.J. Benoliel, Determination of several pesticides in water by solid-phase extraction, liquid chromatography and electrospray tandem mass spectrometry, J. Chromatogr. A 1150 (2007) 267-278.

[7] C. Lourencetti, M.R.R. Marchi, M.L. Ribeiro, Determination of sugar cane herbicides in soil and soil treated with sugar cane vinasse by solid-phase extraction and HPLC-UV, Talanta 77 (2008) 701.

[8] P. Sharma, S. Gandhi, A. Chopra, N. Sekar, C.R. Suri, Fluoroimmunoassay based on suppression of fluorescence self-quenching for ultra-sensitive detection of herbicide diuron, Anal. Chim. Acta 676 (2010) 87-92.

[9] A.R. Solangi, S.G. Memon, A. Mallah, N. Memon, M.Y. Khuhawar, M.I. Bhanger, Development and implication of a capillary electrophoresis methodology for ciprofloxacin, paracetamol and diclofenac sodium in pharmaceutical formulations and simultaneously in human urine samples, Pak. J. Pharm. Sci. 24 (2011) 539-544.

[10] T. Mugadza, T. Nyokong, Facile electrocatalytic oxidation of diuron on polymerized nickel hydroxo tetraamino-phthalocyanine modified glassy carbon electrodes, Talanta 81 (2010) 1373-1379.

[11] J.-M. Zen, A.S. Kumar, D.-M. Tsai, Recent updates of chemically modified electrodes in analytical chemistry, Electroanalysis 15 (2003) 1073-1087.

[12] O.A. Farghaly, R.S.A. Hameed, A.-A.H. Abu-Nawwas, Analytical application using modern electrochemical techniques, International Journal of Electrochemical Science 9 (2014) 3287-3318.

[13] M.B. Gholivand, M. Torkashvand, G. Malekzdeh, Fabrication of an electrochemical sensor based on computationally designed molecularly imprinted polymers for determination of cyanazine in food samples, Anal. Chim. Acta 3 (2012) 36-44.

[14] G. Vasapollo, R.D. Sole, L. Mergola, M.R. Lazzo, A. Scardino, S. Scorrano, G. Mele, Molecularly Imprinted Polymers: Present and Future Prospective, Int. J. Mol. Sci. 12 (2011) 5908-5945.

[15] M. Hussain, J. Wackerlig, P.A. Lieberzeit, Biomimetic Strategies for Sensing Biological Species, Biosensors 3 (2003) 89-107.

[16] D.A. Spivak, Optimization, evaluation, and characterization of molecularly imprinted polymers, Advanced Drug Delivery Reviews 57 (2005) 1779-1794.

[17] M.C. Blanco-López, M.-J. Lobo-Castanon, A.J. Miranda-Ordieres, P. TunónBlanco, Voltammetric response of diclofenac-molecularly imprinted film modified carbon electrodes, Anal Bioanal Chem 377 (2003) 257-261.
[18] K.P. Singh, S. Ahalawat, R.K. Prajapati, S. Kumar, P. Singh, D.S. Kumar, Electrochemical sensing for the detection of 2,4-dichlorophenoxy acetic acid using molecularly imprinted polymer membrane, Ionics 16 (2010) 529-537.

[19] X.-Y Xu, X.-G Tian, L-G. Cai, Z-L. Xu, H.-T. Lei, H. Wang Y.-M. Sun, Molecularly imprinted polymer based surface plasmon resonance sensors for detection of Sudan dyes, Anal. Methods 6 (2014) 3751-3757.

[20] G.F. Coelho, A.C.G. Junior, C.R.T. Tarley, J. Casarin, H. Nacke, M.A Francziskowski, Removal of metal ions $\mathrm{Cd}$ (II), $\mathrm{Pb}$ (II) and $\mathrm{Cr}$ (III) from water by the cashew nut shell Anacardium occidentale L, Ecological Engineering 73 (2014) 514-525.

[21] C.R.T. Tarley, N.C.B. Farias, G.F.L.F.M. Oliveira, R.B.D.C. Dragunski, D.C. Nobile, M G. Segatelli, Crosslinked Poly (4-Vinylpyridine-Ethylene Glycol Dimethacrylate) Used for Preconcentration of Cd II) and its Determination by Flow Injection Flame Atomic Absorption Spectrometry, Journal of AOAC International 97 (2014) 605-611.

[22] R. Zou, J. Hu, Y. Song, N. Wang, H. Chen, H. Chen, J. Wu, Y. Sun, Z. Chen, Carbon nanotubes as field emitter, J. Nanosci. Nanotechnol. 10 (2010) 7876-7896.

[23] S.J. Tans, M.H. Devoret, H. Dai, A. Thess, R.E. Smalley, L.J. Geerligs, C. Dekker, Nature 386 (1997) 474-477.

[24] C. Casas, W. Li, A review of application of carbon nanotubes for lithium ion battery anode material, J. Power Sources 208 (2012) 74-85.

[25] Y. Che, H. Chen, H. Gui, J. Liu, B. Liu, C. Zhou, Review of carbon nanotube nanoelectronics and macroelectronics, Semicond. Sci. Technol. 29 (2014) 1-17.

[26] C. Hu, S. Hu, Carbon nanotube-based electrochemicals sensors: principles and applications in biomedical systems, J. Sensors 2009 (2009) 1-41.

[27] A. Wong, M.R.V. Lanza, M.D.P.T. Sotomayor, Development and application of a highly selective biomimetic sensor for detection of captopril, an important ally in hypertension control, Comb. Chem. High Throughput Screening 13 (2010) 666-674.

[28] F.C. Vicentini, B.C. Janegitz, C.M.A. Brett, O. Fatibello-Filho, Tyrosinase biosensor based on a glassy carbon electrode modified with multi-walled carbon nanotubes and 1-butyl-3-methylimidazolium chloride within a dihexadecylphosphate film, Sensors and Actuators B 188 (2013) 1101-1108.

[29] P.A.G. Cormack, A.Z. Elorza, Molecularly imprinted polymers: synthesis and characterisation, Journal of Chromatography B 804 (2004) 173-182.

[30] H. Yan, K.H. Row, Characteristic and Synthetic Approach of Molecularly Imprinted Polymer, Int. J. Mol. Sci. 7 (2006) 155-178.

[31] C. Lourencetti, M.R.R. Marchi, M.L. Ribeiro, Determination of sugar cane herbicides in soil and soil treated with sugar cane vinasse by solid-phase extraction and HPLC-UV, Talanta 77 (2008) 701-709.

[32] A. Wong, M.D.P.T. Sotomayor, Determination of carbofuran and diuron in FIA system using electrochemical sensor modified with organometallic complexes and graphene oxide, J. Electroanal. Chem. 731 (2014) 163-171.

[33] J.A. Ardila, G.G. Oliveira, R.A. Medeiros, O. Fatibello-Filho, Determination of gemfibrozil in pharmaceutical and urine samples by square wave adsorptive stripping voltammetry using a glassy carbon electrode modified with multiwalled carbono nanotubes within a dihexadecyl hydrogen phosphate filme, J. Electroanal. Chem. 690 (2013) 32-37.

[34] M.A. Rahman, P. Kumar, D.-S. Park, Y.-B. Shim, Electrochemical Sensors Based on Organic Conjugated Polymers, Sensors 8 (2008) 118-141.

[35] P. Sharma, K. Sablok, V. Bhalla, C.R. Suri, A novel disposable electrochemical immunosensor for phenyl urea herbicide diuron, Biosens. Bioelectron. 26 (2011) 4209-4212.

[36] J. Masojıdek, P. Soucek, J. Machova, J. Frolık, K. Klem, J. Maly, Detection of photosynthetic herbicides: Algal growth inhibition test vs. electrochemical photosystem II biosensor, Ecotoxicology and Environmental Safety 74 (2011) 117-122. 